\title{
The Impact of Smoking Status on the Long-Term Prognosis of Male Patients Underwent Percutaneous Coronary Intervention of Left Main Coronary Artery
}

\section{Shu-bin QIAO ( $\square$ qsbfuwai2020@163.com )}

Chinese Academy of Medical Sciences \& Peking Union Medical College Fuwai Hospital https://orcid.org/0000-0002-4232-5116

\section{TENG Hao-bo}

Chinese Academy of Medical Sciences \& Peking Union Medical College Fuwai Hospital GUO Chao

Chinese Academy of Medical Sciences \& Peking Union Medical College Fuwai Hospital

\section{GUAN Chang-dong}

Chinese Academy of Medical Sciences \& Peking Union Medical College Fuwai Hospital

\section{WANG Xin-yu}

Chinese Academy of Medical Sciences \& Peking Union Medical College Fuwai Hospital

\section{XU Hao-bo}

Chinese Academy of Medical Sciences \& Peking Union Medical College Fuwai Hospital

\section{CHUN Yu-shi}

Chinese Academy of Medical Sciences \& Peking Union Medical College Fuwai Hospital

\section{WANG Juan}

Chinese Academy of Medical Sciences \& Peking Union Medical College Fuwai Hospital

\section{YUAN Jian-song}

Chinese Academy of Medical Sciences \& Peking Union Medical College Fuwai Hospital

\section{YANG Wei-xian}

Chinese Academy of Medical Sciences \& Peking Union Medical College Fuwai Hospital XU Bo

Chinese Academy of Medical Sciences \& Peking Union Medical College Fuwai Hospital

\section{Research article}

Keywords: Smoking, Male, Left main coronary artery, Percutaneous Coronary Intervention, Prognosis

Posted Date: October 12th, 2020 
DOI: https://doi.org/10.21203/rs.3.rs-73519/v1

License: (a) (i) This work is licensed under a Creative Commons Attribution 4.0 International License. Read Full License 


\section{Abstract}

Objective: To evaluate the impact of smoking status on the long-term prognosis of male patients with left main coronary artery lesions who received percutaneous coronary intervention.

Methods: A retrospective analysis was conducted. A total of 3122 male patients with left main lesions who received percutaneous coronary intervention in our hospital were categorized by smoking status at admission: 1207 in the non-smokers group, 1339 in the current smokers group, and 576 in the ex-smokers group. The patients were followed up for 3 years. The main study endpoints were major cardiovascular adverse events (composite endpoints of all-cause death, all myocardial infarctions and revascularization) and target lesion failure (composite endpoints of cardiogenic death, target vessel-related myocardial infarction, target vessel-related blood flow reconstruction).

Results: The patients in the current smokers group was younger than the non-smokers group and the exsmokers group $(p<0.0001)$. In terms of prognosis, no statistical significance observed in the incidence of composite end point of MACE $(p=0.9866)$, target lesion failure $(p=0.2522)$, and stent thrombosis $(p=0.2118)$, all-cause death $(p=0.3130)$, cardiogenic death $(p=0.2509)$, revascularization $(p=0.5028)$, target vessel-related revascularization $(p=0.9866)$, and stroke $(p=0.3895)$, among the three groups. The current smokers group had the lowest incidence of myocardial infarction while ex-smokers group had the highest incidence rate(5.67\%vs.5.10\%vs. $2.97 \%, p=0.0072)$, and so is the incidence of myocardial infarction related to target vessels (5.48\%vs.5.10\%vs. $2.89 \%, \mathrm{p}=0.0067)$. According to Cox regression analysis, history of myocardial infarction( $\mathrm{HR}=1.339 \otimes 95 \% \mathrm{Cl} \otimes 1.042-1.722 \rrbracket \mathrm{p}=0.0227)$, and baseline SYNTAX score $(\mathrm{HR}=1.0333,95 \% \mathrm{Cl}: 1.017-1.049, \mathrm{p}<0.0001)$ are independent risk factors of MACE, while current smoking $(\mathrm{HR}=0.793,95 \% \mathrm{Cl} \otimes 0.646-0.974, \mathrm{p}=0.0274)$ proves to be an independent protective factor of target vessel related myocardial infarction.

Conclusion: For male patients with the left main coronary artery lesions receiving $\mathrm{PCl}$, smoking has no impact on the long-term MACE or target lesion failure, current smoking is an independent protective factor for target vessel related myocardial infarction.

\section{Introduction}

Multiple factors contributed to the pathogenesis of coronary atherosclerotic heart disease, including irreversible factors (such as genetics, age, and gender) and reversible factors (such as hypertension, hyperlipidemia, smoking, obesity, etc.).Smoking is recognized as an important risk factor for atherosclerosis and coronary heart disease ${ }^{[1,2]}$, however, with the introduction of the smoker's paradox ${ }^{[3]}$, more and more studies have observed that in patients with coronary heart disease, especially myocardial infarction, the impact of smoking on the long-term prognosis of patients undergoing percutaneous coronary intervention $(\mathrm{PCl})$ is widely controversial ${ }^{[4-6]}$, and smoking cessation has been proven to improve the long-term survival of patients with coronary heart disease ${ }^{[7,8]}$. At present, there are limited studies focused on population with left main coronary artery (LMCA) disease receiving PCl. This study 
aims to investigate the impact of smoking on the long-term clinical prognosis in male patients with LMCA disease who received $\mathrm{PCl}$ in our hospital.

\section{Materials And Methods}

\section{Subjects:}

A total of 3122 male patients with LMCA lesions undergoing PCI from January 2004 to December 2015 were consecutively enrolled in the Department of Cardiology of our hospital. 3,005 patients were followed up for 3 years and the medical records were complete. Inclusion criteria for PCl: life expectancy greater than 5 years; patients with episodes of ischemic symptoms despite optimal medical therapy, etc. Exclusion criteria: 1. Patients with life expectancy $<5$ years. 2. Patients with severe cardiac insufficiency and the left ventricular ejection fraction (LVEF) $<30 \%$.3.Patients with severe respiratory failure, renal insufficiency, liver insufficiency, etc. 4. Patients known to be severely allergic to the contrast agents. 5 . Patients with bleeding disorders who cannot tolerate long-term dual anti-platelet therapy.

\section{Methods:}

Baseline data, laboratory examinations and information of stent implantation were recorded in a dedicated database. A retrospective evaluation was performed for angiography of lesions (including Syntax score) and operating characteristics by an independent core laboratory (The center laboratory of Cardiovascular Intervention Imaging, Fuwai Hospital of National Cardiovascular Center).SYNTAX score was calculated for $>50 \%$ of stenotic lesions in each vessel, witha diameter $>1.5 \mathrm{~mm}$.

All patients were questioned in detail about their smoking status and smoking habits at the time of study enrollment, and patients who never smoked were categorized as non-smokers; patients with a smoking history of $>3$ months and who still smoked within 3 months prior to PCl were categorized as current smokers; and patients who were former smokers but had quit smoking for at least 3 months prior to the intervention were categorized as ex-smokers. Outpatient or telephone follow-ups were performed for all patients at one month, six months, 1 year and 3 years by specialized agencies. All adverse clinical events (including all-cause death, cardiovascular death, re-admission, myocardial infarction, revascularization, bleeding, etc.) were recorded and evaluated by an independent committee on clinical events.

\section{Procedures and pharmaceutical therapeutics $\square$}

Coronary angiography and $\mathrm{PCl}$ were performed via the radial or femoral artery and were performed primarily by experienced operators. All patients were given dual-antiplatelet therapy preoperatively. Patients for elective PCl were given clopidogrel $75 \mathrm{~m} \mathrm{~g} / \mathrm{d}$ (or ticagrelor $90 \mathrm{mg}$ bid) and aspirin tablets $100 \mathrm{~m} \mathrm{~g} / \mathrm{d}$ for 6 consecutive days preoperatively or a loading dose of clopidogrel 300-600mg (or ticagrelor $180 \mathrm{mg}$ ) and aspirin $300 \mathrm{mg}$ preoperatively. After the operation, anti-platelet treatment was administrated based on the clinician's advice. The use of glycoprotein Ilb/Illa receptor inhibitors was determined by the cardiac interventionalists according to the thrombotic load. All interventional procedures were performed 
by experienced clinicians in accordance with formal procedures. All postoperative patients underwent standardized secondary prevention criteria for coronary intervention.

\section{Outcomes and follow-up}

Observation indicators included: all patients were followed at 1, 6, 9 months and 1,2, and 3 years by outpatient clinic or telephone. The primary endpoint of the study was Major Adverse Cardiovascular Events (MACE), defined as all-cause death, myocardial infarction, and all revascularization. Secondary endpoints were Target Lesion Failure (TLF), and stent thrombosis. TLF included cardiac death, target vessel myocardial infarction, and ischemia-driven target vessel revascularization. Cardiac death: defined as any death due to cardiac causes (e.g., myocardial infarction, low cardiac output, fatal arrhythmias), unwitnessed death, unexplained death, and all deaths associated with the operations and treatments. Target vessel revascularization: defined as any revascularization of the entire major coronary artery and its downstream and branch vessels. Stent thrombosis: all definite and probable stent thrombosis defined by the Academic Research Consortium. All adverse clinical events are adjudicated and evaluated by an independent Clinical Events Committee.

\section{Statistical analysis}

Normal distribution was tested for continuous data. Continuous data that met normal distribution were represented by mean $\pm S D$, while mean values were compared by ANOVA. Continuous data that did not met normal distribution were expressed as quartiles (P25, P75), and differential comparison of mean values was performed by nonparametric test (Kruskal-Wallis test). Intensity of qualitative data was described by percentage. Differential comparison of the percentages of qualitative data between groups was performed by Chi-square test. Survival analysis was performed using Kaplan-Meier test and log-rank test. Cox multivariate regression analysis was conducted based on the results of univariate analysis. A probability value of $<0.05$ was considered statistically significant. All analyses were performed using SAS 9.4 .

This study was approved by the hospital ethics committee.

\section{Results}

A total of 3122 male patients with LMCA disease and received PCl in department of cardiovascular medicine in our hospital from January 2004 to December 2015 were investigated, among which 1207 patients categorized in non-smokers group, 1339 patients in current smokers group, and 576 patients in the ex-smokers group. 3005 patients were followed up for 3 years and complete data were collected.

The baseline demographic characteristics of the three groups were showed in Table 1, the current smokers were younger than the nonsmokers and ex-smokers $(p<0.0001)$. There was statistical significance in previous myocardial infarction, previous $\mathrm{PCl}$, type 2 diabetes, hyperlipidemia, family history of coronary artery disease, chronic obstructive pulmonary disease (COPD) among the three 
groups. The ex-smokers had the poorest clopidogrel adherence, with a lowest proportion of never interrupted use of clopidogrel $(83.80 \%$ vs. $90.06 \%$ vs. $86.89 \%, p=0.0026)$. No significant differences were observed in body mass index, post-coronary artery bypass graft (CABG), stroke, peripheral vascular disease, ejection fraction and incidence of asymptomatic ischemia among the three groups.

The coronary angiography data of the three groups was shown in Table 2, and no statistical differences were observed among the three groups in terms of the number of lesion vessels, LM calcification, and baseline SYNTAX score. The duration of PCl time was longer in the ex-smoker group $(p=0.0200)$ than in the other two groups. The comparison of interventional procedures in three groups, shown in table 3 , no statistical differences were observed in stent implantation, number of LM stents, number of total stents, lesion type, lesion length, bifurcation lesion, stent length, procedural complications, successful treatment of lesions, Intra-Aortic Balloon Pump (IABP) support, the application of intravascular ultrasound ,and fractional flow reserve among the three groups.

In terms of prognosis, no statistical differences were observed in composite MACE endpoints $(p=0.2772)$, target lesion failure $(p=0.2522)$, and stent thrombosis $(p=0.2118)$ among the three groups. No statistical difference was observed in the incidence of cardiac death $(p=0.2509)$, target vessel revascularization $(p=0.9866)$, all-cause death $(p=0.3130)$, all revascularization $(p=0.5028)$ and stroke $(p=0.3985)$.The incidence of all myocardial infarction ( $5.67 \%$ vs. $5.10 \%$ vs. $2.97 \%, p=0.0072)$ and target vessel myocardial infarction ( $5.48 \%$ vs. $5.10 \%$ vs. $2.89 \%, p=0.0067$ ) were higher in the ex-smoking group than in non-smokers group and the current smokers group, with statistical difference. The Kaplan-Meier survival curves for MACE and TLF were based on follow-up, starting after PCl, were shown in Figures 1-2.

To investigate the independent risk factors for the composite MACE endpoint, target lesion failure, and the occurrence of each important component event: age, body mass index, smoking status, previous $\mathrm{PCl}$, previous $C A B G$, previous myocardial infarction, hypertension, diabetes, stroke, peripheral vascular disease, preoperative creatinine clearance, and baseline SYNTAX score were included in the cox regression analysis, and the results were shown in Table 5. Smoking was the independent protective factors for the occurrence of target vessel myocardial infarction ( $\mathrm{HR}=0.793,95 \% \mathrm{Cl}: 0.646-0.974$, $p=0.0274$ ), whereas for MACE, target lesion failure, cardiac death, all-cause death, and target vessel revascularization, smoking were neither risk nor protective factors. Previous myocardial infarction $(\mathrm{HR}=1.339,95 \% \mathrm{Cl}: 1.042-1.722, \mathrm{p}=0.0227)$ and baseline SYNTAX score (HR=1.0333, 95\% Cl: 1.017-1.049, $\mathrm{p}<0.0001)$ were independent risk factors.

\section{Discussion}

Smoking, as a clear risk factor for coronary heart disease, can induce endothelial damage, inflammatory response, plaque erosion and rupture, leading to endothelial dysfunction and vasodilatation, and ultimately atherosclerosis progression, increasing the risk of myocardial infarction ${ }^{[9-11]}$. The finding of a survival benefit from smoking in patients with acute myocardial infarction has led to the introduction of the smoker's paradox ${ }^{[3]}$, with speculation that possible mechanisms including the relatively younger age 
of smokers, fewer risk factors, better clopidogrel responsiveness and therefore better platelet suppression ${ }^{[12]}$,the high pre-hospital mortality in smokers may lead to biased findings ${ }^{[13]}$ and an increased incidence of deep vein thrombosis after smoking cessation ${ }^{[14]}$, etc.

A recent meta-analysis showed that the mortality rate was lower in smokers with ACS at 30 days $(2.3 \%$ vs. $3.3 \%, \mathrm{OR}=0.54,95 \% \mathrm{Cl}: 0.39-0.76, \mathrm{p}<0.001), 12$ months (2.3\% vs. $3.6 \%, \mathrm{OR}=0.54,95 \% \mathrm{Cl}: 0.30-0.70$, $p<0.001)$, and this decrease is associated with younger age, lower incidence of diabetes, less severe coronary lesions, and male sex ratio ${ }^{[15]}$. However, most of the studies supporting this paradox originated in the thrombolytic and early $\mathrm{PCl}$ era. Few studies were based on the post-PCl era, which was recently supplemented by Parasuraman et al. In a cohort study including 12,656 patients with non-elective $\mathrm{PCl}$, smokers underwent $\mathrm{PCl}$ at an earlier age and were more likely to undergo $\mathrm{PCl}$ for acute coronary syndromes and had an increased 30-day mortality rate compared to non-smokers ${ }^{[16]}$.

Ndrepepa et al. observed a lower incidence of no-reflow in smokers than in nonsmokers in the population undergoing emergency PCI for STEMI ${ }^{[17]}$, but this can be explained by the younger age of the smokers, fewer cardiovascular risk factors comorbid and a higher thrombotic component in the study. Shemirani et al. further showed that after adjusting for confounding factors such as age, no significant differences were observed between smokers and nonsmokers in the no-reflow phenomena and short-term complications ${ }^{[18]}$, consistent with the findings of Sherif's team ${ }^{[19]}$. In the non-ST-segment elevation myocardial infarction population, Feistritzer demonstrated that smoking status had no effect on infarction size, microcirculatory obstruction, or MACE development ${ }^{[20]}$ by Magnetic Resonance Imaging, which challenged the smoker's paradox to varying degrees.

LM lesions used to be considered off-limits to $\mathrm{PCl}$, but with the increasing development of interventional techniques, $\mathrm{PCI}$ has become the main treatment for LM lesions ${ }^{[21,22]}$. The EXCEL study included 1,905 patients with $\mathrm{LM}$ lesions, randomized to $\mathrm{PCl}$ and $\mathrm{CABG}$, showed an increased incidence of the 5-year composite endpoint in current smokers compared with nonsmokers, with no increased risk seen in exsmokers ${ }^{[23]}$. The SYNTAX study was also performed in patients with more complex coronary artery disease and dynamically observed the smoking status of patients during the follow-up period, and similar conclusions were yield with further analysis ${ }^{[24]}$.

In our study, smoking did not affect the incidence of MACE or TLF in this population, only that the incidence of myocardial infarction and target vessel-related myocardial infarction was lower in current smokers. According to the baseline data, the younger of current smokers, the higher incidence of previous myocardial infarction and the more history of $\mathrm{PCl}$ all suggested that this population had an earlier onset of coronary heart disease and fewer co-existing high-risk factors, and the creatinine clearance rate was higher than the other two groups, which can also partially explain the lower incidence of postoperative myocardial infarction, target vessel-related myocardial infarction and hemorrhage in current smokers. In addition, smoking status can change over the course of follow-up, with the possibility of relapse in exsmokers and gradual smoking cessation in current smokers, but the vast majority of studies have just 
examined smoking status at baseline and were performed with post-hoc analysis, limiting the accuracy of the results to some extent.

Although the impact of smoking on long-term prognosis is still not completely clear, there is no doubt that adherence to smoking cessation is important.A meta-analysis including 12,603 smokers with coronary artery disease showed that smoking cessation after acute myocardial infarction or cardiac surgery significantly decreased the mortality rate $(\mathrm{RR}=0.64,95 \% \mathrm{Cl}: 0.58-0.71)^{[26]}$, and after $\mathrm{PCl}$ treatment, compared to smoking cessation patients, those who continue to smoke have worse health-related quality of life and a higher frequency of angina attack symptoms ${ }^{[8]}$. However, the rate of smoking cessation in patients undergoing $\mathrm{PCl}$ and pharmacotherapy is lower than that of in $\mathrm{CABG}{ }^{[7]}$, so there is still much work to be done to promote smoking cessation and manage patients in clinical practice.

Although this study is a large-scale study of the population undergoing PCI for LM lesions, there are still certain limitations in the following aspects: 1 ) the study is a retrospective observational study; 2) the study is a single center study, with a small sample size and only male patients, and the ex-smoking group is significantly smaller than the other two groups, which reduces the statistical efficiency; 3 ) the smoking status is only evaluated before enrollment, and the cigarette consumption and duration is missing,which limits the quantitative analysis of the impact of smoking on long-term prognosis. In the future, a multicenter study on smoking status can be conducted to further expand the sample size, adequately match the population of three groups, extend the follow-up time, continue to improve the observation of smoking status during the follow-up period, and conduct quantitative statistics on the cigarettes consumption and the duration of smoking, so as to better verify the predictive ability of smoking as an important risk factor for the long-term prognosis of patients undergoing PCl for LM lesions.

\section{Conclusion}

Smoking status has no effect on the long-term MACE or target lesion failure in male patients undergoing $\mathrm{PCl}$ for left main stem lesions.

\section{Declarations}

\section{Ethical Approval and Consent to participate}

The Ethics Committee of the Fuwai Hospital, National Center for Cardiovascular Diseases, Chinese Academy of Medical Sciences and Peking Union Medical College approved the study protocol with written informed consent from patients or their next of kin and the use of deferred consent.

\section{Consent for publication}

Consent for publication has been approved by Fuwai Hospital, National Center for Cardiovascular Diseases, Chinese Academy of Medical Sciences and Peking Union Medical College. 
Availability of supporting data

The datasets used and/or analyzed during the current study are available from the corresponding author on reasonable request.

\section{Competing interests}

All the authors declare that they have no competing interests.

\section{Funding}

Not applicable

\section{Authors' contributions}

GC, THB contributed equally as the first author, drafted the manuscript, YWX XB and QSB created the idea of the study. WXY, GCD, WJ, XHB conducted the analyses. CYS, YJS critically reviewed the manuscript and agreed with the final version and findings. All authors read and approved the final manuscript.

\section{Acknowledgements}

Not applicable

\section{Authors' information}

1Center of Coronary Heart Disease, National Center for Cardiovascular Diseases and Fuwai Hospital, Chinese Academy of Medical Sciences and Peking Union Medical College, Beijing, 100037, China.

\section{References}

1. Virtanen M, Vahtera J, Singh-Manoux A, et al. Unfavorable and favorable changes in modifiable risk factors and incidence of coronary heart disease: The Whitehall II cohort study[J]. Int J Cardiol. 2018;269:7-12. DOI:10.1016/j.ijcard.2018.07.005.

2. Carter BD, Abnet CC, Feskanich D, et al. Smoking and mortality-beyond established causes[J]. N Engl J Med. 2015;372(7):631-40. DOI:10.1056/NEJMsa1407211.

3. Barbash GI, Reiner J, White HD, et al. Evaluation of paradoxic beneficial effects of smoking in patients receiving thrombolytic therapy for acute myocardial infarction: mechanism of the "smoker's paradox" from the GUSTO-I trial, with angiographic insights[J]. Global Utilization of Streptokinase and Tissue-Plasminogen Activator for Occluded Coronary Arteries[J]. J Am Coll Cardiol. 1995;26(5):1222-9. DOI:. 10.1016/0735-1097(95)00299-5.

4. Andrikopoulos GK, Richter DJ, Dilaveris PE, et al. In-hospital mortality of habitual cigarette smokers after acute myocardial infarction; the "smoker's paradox" in a countrywide study[J]. Eur Heart J. 2001;22(9):776-84. DOI:10.1053/euhj.2000.2315. 
5. Liu R, Gao Z, Wang H, et al. Association of Baseline Smoking Status with Long-Term Prognosis in Patients Who Underwent Percutaneous Coronary Intervention: Large Single-Center Data[J]. J Interv Cardiol. 2019;2019:3503876. DOI:10.1155/2019/3503876.

6. Coutinho Cruz M, Ilhão Moreira R, Abreu A, et al. The smoker's paradox in acute coronary syndrome: Is it real? [J]. Rev Port Cardiol. 2018;37(10):847-55. DOl:10.1016/j.repc.2017.12.005.

7. Hammal F, Ezekowitz JA, Norris CM, et al. Smoking status and survival: impact on mortality of continuing to smoke one year after the angiographic diagnosis of coronary artery disease, a prospective cohort study[J]. BMC Cardiovasc Disord. 2014;14:133. DOI:10.1186/1471-2261-14-133.

8. Jang JS, Buchanan DM, Gosch KL, et al. Association of smoking status with health-related outcomes after percutaneous coronary intervention[J]. Circ Cardiovasc Interv 2015;8(5).

DOI:10.1161/circinterventions.114.002226.

9. Auerbach O, Carter HW, Garfinkel L, et al. Cigarette smoking and coronary artery disease. A macroscopic and microscopic study[J]. Chest. 1976;70(6):697-705. DOI:10.1378/chest.70.6.697.

10. Ambrose JA, Barua RS. The pathophysiology of cigarette smoking and cardiovascular disease: an update[J]. J Am Coll Cardiol. 2004;43(10):1731-7. DOI:10.1016/j.jacc.2003.12.047.

11. Burke AP, Farb A, Malcom GT, et al. Effect of risk factors on the mechanism of acute thrombosis and sudden coronary death in women[J]. Circulation. 1998;97(21):2110-6.

DOI:10.1161/01.cir.97.21.2110.

12. Gurbel PA, Bliden KP, Logan DK, et al. The influence of smoking status on the pharmacokinetics and pharmacodynamics of clopidogrel and prasugrel: the PARADOX study[J]. J Am Coll Cardiol. 2013;62(6):505-12. DOI:10.1016/j.jacc.2013.03.037.

13. Schatzkin A, Cupples LA, Heeren T, et al. Sudden death in the Framingham Heart Study. Differences in incidence and risk factors by sex and coronary disease status[J]. Am J Epidemiol. 1984;120(6):888-99. DOI:10.1093/oxfordjournals.aje.a113960.

14. Handley AJ, Teather D. Influence of smoking on deep vein thrombosis after myocardial infarction[J]. Br Med J 1974;3(5925):230-1. 10. DOI:1136/bmj.3.5925.230.

15. Sharma SP, Dahal K, Rijal J, et al. Meta-Analysis Comparing Outcomes of Smokers Versus Nonsmokers With Acute Coronary Syndrome Underwent Percutaneous Coronary Intervention[J]. Am J Cardiol. 2018;122(6):973-80. DOI:10.1016/j.amjcard.2018.05.045.

16. Parasuraman S, Zaman AG, Egred M, et al. Smoking status and mortality outcomes following percutaneous coronary intervention[J]. Eur J Prev Cardiol 2020:2047487320902325. DOI: $10.1177 / 2047487320902325$.

17. Ndrepepa G, Mehilli J, Schulz S, et al. Prognostic significance of epicardial blood flow before and after percutaneous coronary intervention in patients with acute coronary syndromes[J]. J Am Coll Cardiol. 2008;52(7):512-7. DOI:10.1016/j.jacc.2008.05.009.

18. Shemirani H, Tafti FD, Amirpour A. Comparison of no-reflow phenomenon after percutaneous coronary intervention for acute myocardial infarction between smokers and nonsmokers[J]. J Res Med Sci. 2014;19(11):1068-73. DOI:10.1186/s12931-020-01399-9. 
19. Sherif MA, Nienaber CA, Toelg R, et al. Impact of smoking on the outcome of patients treated with drug-eluting stents: 1-year results from the prospective multicentre German Drug-Eluting Stent Registry (DES.DE) [J]. Clin Res Cardiol. 2011;100(5):413-23. DOI:10.1007/s00392-010-0259-y.

20. Feistritzer HJ, Eitel I, Jobs A, et al. Impact of smoking on cardiac magnetic resonance infarct characteristics and clinical outcome in patients with non-ST-elevation myocardial infarction. Int $J$ Cardiovasc Imaging. 2019;35(6):1079-87. DOI:10.1007/s10554-019-01556-2[J].

21. Mäkikallio T, Holm NR, Lindsay $M$, et al. Percutaneous coronary angioplasty versus coronary artery bypass grafting in treatment of unprotected left main stenosis (NOBLE): a prospective, randomised, open-label, non-inferiority trial[J]. Lancet. 2016;388(10061):2743-52. DOI:10.1016/s01406736(16)32052-9.

22. Nagarajarao HS, Ojha CP, Mulukutla V, et al. Current Use and Trends in Unprotected Left Main Coronary Artery Percutaneous Intervention[J]. Curr Cardiol Rep. 2020;22(4):16. DOI:10.1007/s11886020-1268-8.

23. Shahim B, Redfors B, Chen S, et al. Outcomes After Left Main Coronary Artery Revascularization by Percutaneous Coronary Intervention or Coronary Artery Bypass Grafting According to Smoking Status [J]. Am J Cardiol. 2020. DOI:10.1016/j.amjcard.2020.04.029.

24. Zhang YJ, Iqbal J, van Klaveren D, et al. Smoking is associated with adverse clinical outcomes in patients undergoing revascularization with PCI or CABG: the SYNTAX trial at 5-year follow-up[J]. J Am Coll Cardiol. 2015;65(11):1107-15. DOI:10.1016/j.jacc.2015.01.014.

25. Wang J, Guan CD,Yuan JS, et al, Characteristics of Coronary Artery Lesions in Smokers With Coronary Heart Disease and Prognostic Evaluation After Percutaneous Coronary Intervention [J].Chinese Circulation Journal 2018.33(11):1053-1058.DOI: DOI: 10. 3969/j. issn. 1000-3614. 2017. 06. 001.

26. Critchley JA, Capewell S. Mortality risk reduction associated with smoking cessation in patients with coronary heart disease: a. systematic review[J]Jama. 2003;290(1):86-97.

DOI:10.1001/jama.290.1.86.

\section{Tables}

Table 1. Comparison of baseline data of patients classified according to smoking status 


\begin{tabular}{|c|c|c|c|c|}
\hline \multirow[t]{2}{*}{ Indicator } & \multirow[t]{2}{*}{$\begin{array}{l}\text { non-smokers } \\
\bigotimes n=1207 \rrbracket\end{array}$} & $\begin{array}{l}\text { Current } \\
\text { smokers }\end{array}$ & \multirow[t]{2}{*}{$\begin{array}{l}\text { ex-smokers } \\
\text { 冈n=576】 }\end{array}$} & \multirow[t]{2}{*}{$P$ value } \\
\hline & & $\bigotimes n=1339 \square$ & & \\
\hline $\operatorname{Age}(X \pm S)$ & $61.42 \pm 10.54$ & $57.26 \pm 10.07$ & $61.04 \pm 9.88$ & $<0.0001$ \\
\hline Body mass index ( $X \pm S)$ & $25.69 \pm 3.02$ & $25.79 \pm 3.17$ & $25.69 \pm 2.92$ & 0.6810 \\
\hline Post-myocardial infarction & $281(23.28 \%)$ & $430(32.11 \%)$ & 177(30.73\%) & $<0.0001$ \\
\hline Post-PCl & $284(23.53 \%)$ & $347(25.91 \%)$ & 198(34.38\%) & $<0.0001$ \\
\hline Post-CABG & $41(3.40 \%)$ & $27(2.02 \%)$ & $16(2.78 \%)$ & 0.0982 \\
\hline Type 2 diabetes mellitus & $293(24.28 \%)$ & $355(26.51 \%)$ & $173(30.03 \%)$ & 0.0346 \\
\hline Hypertension & $623(51.62 \%)$ & $751(56.09 \%)$ & $355(61.63 \%)$ & 0.0003 \\
\hline Hyperlipidemia & $629(52.11 \%)$ & $780(58.25 \%)$ & $363(63.02 \%)$ & $<0.0001$ \\
\hline Family history of CAD & $156(13.17 \%)$ & $317(23.67 \%)$ & $102(17.71 \%)$ & $<0.0001$ \\
\hline Stroke & $103(8.53 \%)$ & $130(9.71 \%)$ & $65(11.28 \%)$ & 0.1746 \\
\hline Peripheral vascular diseases & $84(6.96 \%)$ & $88(6.57 \%)$ & $41(7.12 \%)$ & 0.8839 \\
\hline $\begin{array}{l}\text { Chronic obstructive pulmonary } \\
\text { disease }\end{array}$ & $7(0.58 \%)$ & $5(0.37 \%)$ & $9(1.56 \%)$ & 0.0205 \\
\hline $\begin{array}{l}\text { Creatinine Clearance } \\
\text { Rate(m//min, ' } X \pm S)\end{array}$ & $88.50 \pm 25.98$ & $97.08 \pm 27.87$ & $89.40 \pm 28.94$ & $<0.0001$ \\
\hline Ejection fraction(\%, $X \pm S)$ & $62.97 \pm 7.60$ & $62.71 \pm 8.06$ & $62.72 \pm 7.67$ & 0.6911 \\
\hline Asymptomatic ischemia & $95(7.87 \%)$ & $116(8.66 \%)$ & $40(6.94 \%)$ & 0.1811 \\
\hline Clopidogrel adherence & $1147(\%)$ & $1236(\%)$ & $537(\%)$ & \\
\hline Never interrupted & 1033(90.06\%) & 1047(86.89\%) & $450(83.80 \%)$ & \\
\hline Occasional interrupted & $96(8.37 \%)$ & $137(11.08 \%)$ & $77(14.34 \%)$ & 0.0026 \\
\hline long-term interrupted & $13(1.13 \%)$ & $16(1.29 \%)$ & $10(1.86 \%)$ & \\
\hline occasional dose & $5(0.44 \%)$ & $9(0.73 \%)$ & $0(0.00 \%)$ & \\
\hline
\end{tabular}

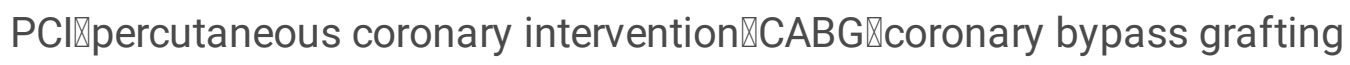

Table 2.Comparison of coronary artery disease based on smoking status 


\begin{tabular}{|c|c|c|c|c|}
\hline Indicator & $\begin{array}{l}\text { non-smokers } \\
\bigotimes n=1207 \rrbracket\end{array}$ & $\begin{array}{l}\begin{array}{l}\text { Current } \\
\text { smokers }\end{array} \\
\bigotimes n=1339 \rrbracket\end{array}$ & $\begin{array}{l}\text { ex-smokers } \\
\bigotimes n=576 \rrbracket\end{array}$ & $\begin{array}{l}P \\
\text { value }\end{array}$ \\
\hline Imaging diagnosis & & & & 0.2270 \\
\hline $\mathrm{LM}+0$ & $63(5.22 \%)$ & $88(6.57 \%)$ & $35(6.08 \%)$ & \\
\hline $\mathrm{LM}+1$ & $260(21.54 \%)$ & $243(18.15 \%)$ & $107(18.58 \%)$ & \\
\hline $\mathrm{LM}+2$ & $473(39.19 \%)$ & $510(38.09 \%)$ & $229(39.76 \%)$ & \\
\hline $\mathrm{LM}+3$ & $411(34.05 \%)$ & $498(37.19 \%)$ & $205(35.59 \%)$ & \\
\hline $\begin{array}{l}\text { LM calcification } \\
\text { Dominant }\end{array}$ & $160(13.26 \%)$ & $163(12.17 \%)$ & $76(13.19 \%)$ & 0.6783 \\
\hline equilibrium & $51(4.23 \%)$ & $40(2.99 \%)$ & $19(3.30 \%)$ & 0.5047 \\
\hline left & $43(3.56 \%)$ & $52(3.88 \%)$ & $24(4.17 \%)$ & \\
\hline right & $1113(92.21 \%)$ & 1247(93.13\%) & $533(92.53 \%)$ & \\
\hline $\mathrm{PCl}$ duration $₫ \mathrm{~min}$, & $51.79 \pm 35.67$ & $52.71 \pm 37.40$ & $54.04 \pm 33.31$ & 0.0200 \\
\hline Baseline SYNTAX & $23.21 \pm 7.01$ & $23.07 \pm 7.24$ & $23.61 \pm 7.33$ & 0.3782 \\
\hline
\end{tabular}

LM冈left main; PCl: percutaneous coronary intervention.

Table 3. Comparison of left main stem interventions based on smoking status 


\begin{tabular}{|c|c|c|c|c|}
\hline Indicator & $\begin{array}{l}\text { Non-smokers } \\
\bigotimes n=1207 \rrbracket\end{array}$ & $\begin{array}{l}\text { Current } \\
\text { smokers } \\
\text { 冈n=1339® }\end{array}$ & $\begin{array}{l}\text { Ex-smokers } \\
\bigotimes n=576 \rrbracket\end{array}$ & $\begin{array}{l}P \\
\text { value }\end{array}$ \\
\hline Stent implantation & 1190(98.59\%) & 1314(98.13\%) & $568(98.61 \%)$ & 0.5916 \\
\hline Number of LM stents & $2.00 \pm 1.03$ & $1.99 \pm 1.13$ & $2.07 \pm 1.11$ & 0.2150 \\
\hline $\begin{array}{l}\text { Length of LM stents } ₫ \mathrm{~mm} \text {, } \\
X \pm S \unrhd\end{array}$ & $32.30 \pm 19.78$ & $32.68 \pm 20.72$ & $31.88 \pm 19.29$ & 0.9603 \\
\hline Number of $D E S \otimes X \pm S \otimes$ & $2.12 \pm 1.10$ & $2.15 \pm 1.24$ & $2.16 \pm 1.16$ & 0.8760 \\
\hline Post-extention & $864(71.58 \%)$ & $990(73.94 \%)$ & $423(73.44 \%)$ & 0.3923 \\
\hline Lesion length $₫ \mathrm{~mm}, \mathrm{X} \pm \mathrm{S} \rrbracket$ & $27.39 \pm 19.23$ & $27.91 \pm 20.27$ & $27.42 \pm 19.24$ & 0.9988 \\
\hline \multicolumn{5}{|l|}{ Lesion type } \\
\hline De novo & 1172(97.10\%) & 1307(97.61\%) & $553(96.01 \%)$ & 0.1573 \\
\hline Re-stenosis & $35(2.90 \%)$ & $32(2.39 \%)$ & $23(3.99 \%)$ & \\
\hline Radial process & $915(75.81 \%)$ & $1010(75.43 \%)$ & $418(72.57 \%)$ & 0.3064 \\
\hline Bifurcation lesion & $1000(82.85 \%)$ & $1098(82.00 \%)$ & $491(85.24 \%)$ & 0.2234 \\
\hline Operation complications & $28(2.32 \%)$ & $25(1.87 \%)$ & $12(2.08 \%)$ & 0.7376 \\
\hline Successful treatment & 1199(99.34\%) & $1329(99.25 \%)$ & $570(98.96 \%)$ & 0.6613 \\
\hline IABP & $99(8.20 \%)$ & $106(7.92 \%)$ & $32(5.56 \%)$ & 0.1196 \\
\hline IVUS & $464(38.44 \%)$ & $563(42.05 \%)$ & $237(41.15 \%)$ & 0.1696 \\
\hline FFR & $0(0.00 \%)$ & $2(0.15 \%)$ & $1(0.17 \%)$ & 0.4105 \\
\hline
\end{tabular}

LM: left main; DES: drug-eluting stent; IABP: intra-aortic balloon pump; IVUS: intravascular ultrasound; FFR: flow reserve fraction

Table 4. Comparison of 3-year follow-up prognosis based on smoking status 


\begin{tabular}{|c|c|c|c|c|}
\hline \multirow[t]{2}{*}{ Indicators } & \multirow[t]{2}{*}{$\begin{array}{l}\text { Non-smokers } \\
\bigotimes n=1207 \rrbracket\end{array}$} & $\begin{array}{l}\text { Current } \\
\text { smokers }\end{array}$ & \multirow[t]{2}{*}{$\begin{array}{l}\text { Ex-smokers } \\
\bigotimes n=576 \rrbracket\end{array}$} & \multirow[t]{2}{*}{$\begin{array}{l}P \\
\text { value }\end{array}$} \\
\hline & & $\bigotimes n=1339 \bigotimes$ & & \\
\hline $\begin{array}{l}\text { Completion of 3-year } \\
\text { follow-up }\end{array}$ & 1177(97.57\%) & 1281(95.67\%) & $547(94.97 \%)$ & 0.0098 \\
\hline MACE & $121(10.28 \%)$ & $117(9.13 \%)$ & $63(11.52 \%)$ & 0.2772 \\
\hline All-cause death & $44(3.74 \%)$ & $42(3.28 \%)$ & $26(4.75 \%)$ & 0.3130 \\
\hline All MI & $60(5.10 \%)$ & $38(2.97 \%)$ & $31(5.67 \%)$ & 0.0072 \\
\hline All revascularization & $87(7.39 \%)$ & $110(8.59 \%)$ & $47(8.59 \%)$ & 0.5028 \\
\hline Target lesion failure & $105(8.92 \%)$ & $98(7.65 \%)$ & $54(9.87 \%)$ & 0.2522 \\
\hline Cardiac death & $25(2.12 \%)$ & $24(1.87 \%)$ & $17(3.11 \%)$ & 0.2509 \\
\hline TVMI & $60(5.10 \%)$ & $37(2.89 \%)$ & $30(5.48 \%)$ & 0.0067 \\
\hline TVR & $49(4.16 \%)$ & $52(4.06 \%)$ & $23(4.20 \%)$ & 0.9866 \\
\hline Stroke & $23(1.95 \%)$ & $17(1.33 \%)$ & $11(2.01 \%)$ & 0.3985 \\
\hline Stent thrombosis & $19(1.61 \%)$ & $16(1.25 \%)$ & $13(2.38 \%)$ & 0.2118 \\
\hline
\end{tabular}

MACE囚Major adverse cardiovascular events; MI: myocardial infarction; TVMI: Target Vessel-related Myocardial Infarction; TVR: Target vessel revascularization

Table 5a. Results of Cox regression analysis for endpoint events 


\begin{tabular}{|c|c|c|c|c|}
\hline \multirow[t]{2}{*}{ Indicators } & \multicolumn{2}{|l|}{ MACE } & \multicolumn{2}{|c|}{ Target vessel failure } \\
\hline & $P$ value & $\mathrm{HR} \otimes 95 \% \mathrm{CI} \rrbracket$ & $P$ value & 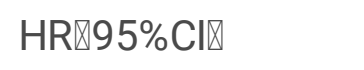 \\
\hline Age (continuous increment) & 0.0507 & $1.015[1.000,1.031]$ & 0.4622 & $1.006[0.990,1.023]$ \\
\hline 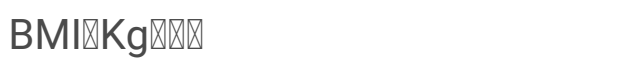 & 0.2522 & $1.026[0.982,1.071]$ & 0.0499 & $1.047[1.000,1.097]$ \\
\hline Smoking & 0.9743 & $0.998[0.874,1.139]$ & 0.5368 & $0.956[0.829,1.103]$ \\
\hline Previous $\mathrm{PCl}$ & 0.0632 & $1.274[0.987,1.644]$ & 0.0500 & $1.316[1.000,1.732]$ \\
\hline Previous CABG & 0.0864 & $0.488[0.215,1.108]$ & 0.1346 & $0.533[0.233,1.216]$ \\
\hline Previous myocardial infarction & 0.0227 & $1.339[1.042,1.722]$ & 0.0200 & $1.379[1.052,1.808]$ \\
\hline Hypertension & 0.4995 & $1.088[0.852,1.389]$ & 0.5552 & $1.083[0.832,1.410]$ \\
\hline Diabetes & 0.6393 & $0.939[0.720,1.224]$ & 0.5337 & $0.913[0.685,1.217]$ \\
\hline Stroke & 0.4758 & $0.867[0.586,1.283]$ & 0.3949 & $0.827[0.533,1.281]$ \\
\hline peripheral vascular disease & 0.8841 & $1.034[0.660,1.620]$ & 0.5931 & $0.866[0.512,1.467]$ \\
\hline Preoperative creatinine clearance & 0.1288 & $0.995[0.988,1.002]$ & 0.0832 & $0.994[0.986,1.001]$ \\
\hline Baseline SYNTAX score & $<0.0001$ & $1.033[1.017,1.049]$ & $<0.0001$ & $1.041[1.024,1.059]$ \\
\hline
\end{tabular}

BMI:body mass index

Table 5b. Results of Cox regression analysis for endpoint events 


\begin{tabular}{|c|c|c|c|c|}
\hline \multirow[t]{2}{*}{ Indicators } & \multicolumn{2}{|c|}{ Cardiac death } & \multicolumn{2}{|c|}{ All-cause death } \\
\hline & $P$ value & 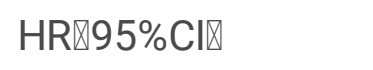 & $P$ value & 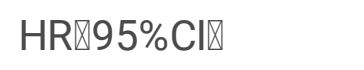 \\
\hline Age (continuous increment) & 0.2143 & $1.022[0.988,1.056]$ & 0.0028 & $1.041[1.014,1.070]$ \\
\hline 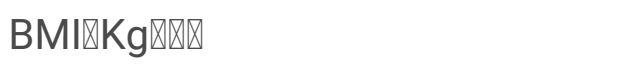 & 0.1731 & $1.065[0.973,1.165]$ & 0.8136 & $1.009[0.939,1.084]$ \\
\hline Smoking & 0.9434 & $0.990[0.745,1.316]$ & 0.6033 & $1.060[0.852,1.318]$ \\
\hline Previous $\mathrm{PCl}$ & 0.7331 & $0.910[0.528,1.568]$ & 0.9856 & $0.996[0.652,1.522]$ \\
\hline Previous CABG & 0.2157 & $0.282[0.038,2.091]$ & 0.1337 & $0.220[0.030,1.592]$ \\
\hline Previous myocardial infarction & $<0.0001$ & $3.709[2.193,6.273]$ & $<0.0001$ & $2.273[1.530,3.378]$ \\
\hline Hypertension & 0.7819 & $1.077[0.638,1.816]$ & 0.7121 & $1.079[0.721,1.615]$ \\
\hline Diabetes & 0.1043 & $0.592[0.314,1.115]$ & 0.4746 & $0.849[0.542,1.330]$ \\
\hline Stroke & 0.1783 & $1.557[0.817,2.966]$ & 0.2810 & $1.330[0.792,2.234]$ \\
\hline peripheral vascular disease & 0.5414 & $0.695[0.216,2.235]$ & 0.9059 & $1.045[0.504,2.166]$ \\
\hline Preoperative creatinine clearance & 0.0673 & $0.986[0.971,1.001]$ & 0.1004 & $0.990[0.978,1.002]$ \\
\hline Baseline SYNTAX score & 0.0042 & $1.048[1.015,1.082]$ & 0.0424 & $1.027[1.001,1.054]$ \\
\hline
\end{tabular}

BMI:body mass index $\triangle \mathrm{CABG} \rrbracket$ coronary artery bypass graft $\triangle \mathrm{PCI} \llbracket$ percutaneous coronary intervention Table 5c. Results of Cox regression analysis for endpoint events 


\begin{tabular}{|c|c|c|c|c|}
\hline \multirow[t]{2}{*}{ Indicators } & \multicolumn{2}{|c|}{$\begin{array}{l}\text { Targeted-vessel } \\
\text { revascularization }\end{array}$} & \multicolumn{2}{|c|}{$\begin{array}{l}\text { Targeted-vessel myocardial } \\
\text { infarction }\end{array}$} \\
\hline & $P$ value & $\mathrm{HR} \otimes 95 \% \mathrm{Cl} \rrbracket$ & $P$ value & HR囚95\%Cl区 \\
\hline Age (continuous increment) & 0.6927 & $0.995[0.972,1.019]$ & 0.3655 & $1.011[0.987,1.035]$ \\
\hline $\mathrm{BM} \otimes \mathrm{Kg} \otimes \mathbb{\|}$ & 0.4014 & $1.029[0.962,1.101]$ & 0.0323 & $1.073[1.006,1.144]$ \\
\hline Smoking & 0.8436 & $0.979[0.797,1.204]$ & 0.0274 & $0.793[0.646,0.974]$ \\
\hline Previous $\mathrm{PCl}$ & 0.0001 & $2.095[1.431,3.066]$ & 0.9053 & $1.025[0.687,1.529]$ \\
\hline Previous CABG & 0.5521 & $1.321[0.527,3.311]$ & 0.0545 & $0.143[0.020,1.038]$ \\
\hline $\begin{array}{l}\text { Previous myocardial } \\
\text { infarction }\end{array}$ & 0.4249 & $0.843[0.554,1.282]$ & 0.0010 & $1.874[1.290,2.724]$ \\
\hline Hypertension & 0.4241 & $1.170[0.796,1.720]$ & 0.6870 & $1.080[0.743,1.570]$ \\
\hline Diabetes & 0.5827 & $1.119[0.750,1.670]$ & 0.5023 & $0.869[0.576,1.310]$ \\
\hline Stroke & 0.1033 & $0.500[0.217,1.151]$ & 0.8888 & $0.960[0.544,1.695]$ \\
\hline peripheral vascular disease & 0.8994 & $0.954[0.462,1.972]$ & 0.5894 & $0.809[0.376,1.745]$ \\
\hline $\begin{array}{l}\text { Preoperative creatinine } \\
\text { clearance }\end{array}$ & 0.6973 & $1.002[0.993,1.011]$ & 0.0537 & $0.990[0.979,1.000]$ \\
\hline Baseline SYNTAX score & 0.1821 & $1.017[0.992,1.044]$ & $<0.0001$ & $1.053[1.029,1.078]$ \\
\hline
\end{tabular}

BMI:body mass index

\section{Figures}




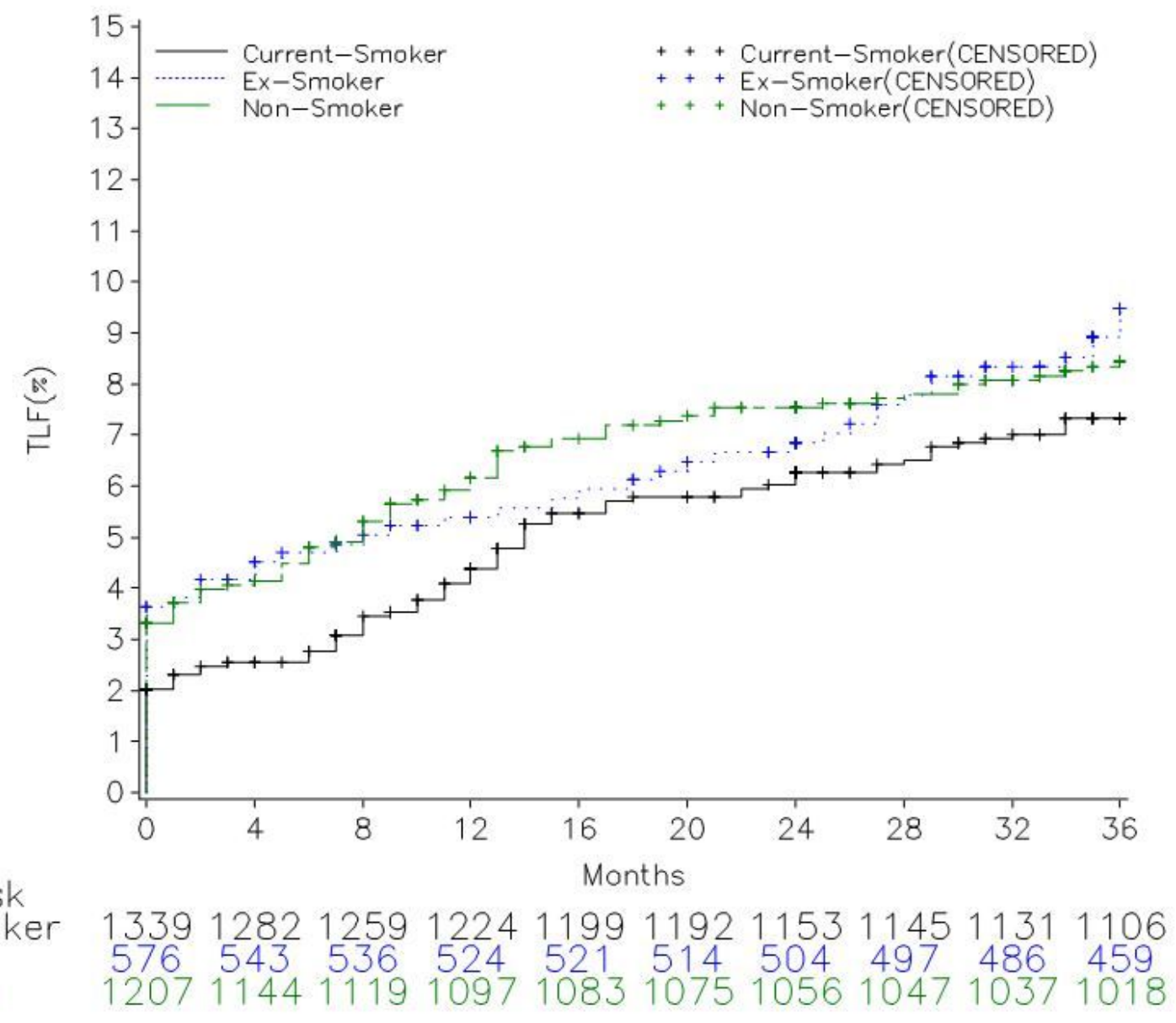

Figure 1

Kaplan-Meier survival curve of Target Lesion Failure 


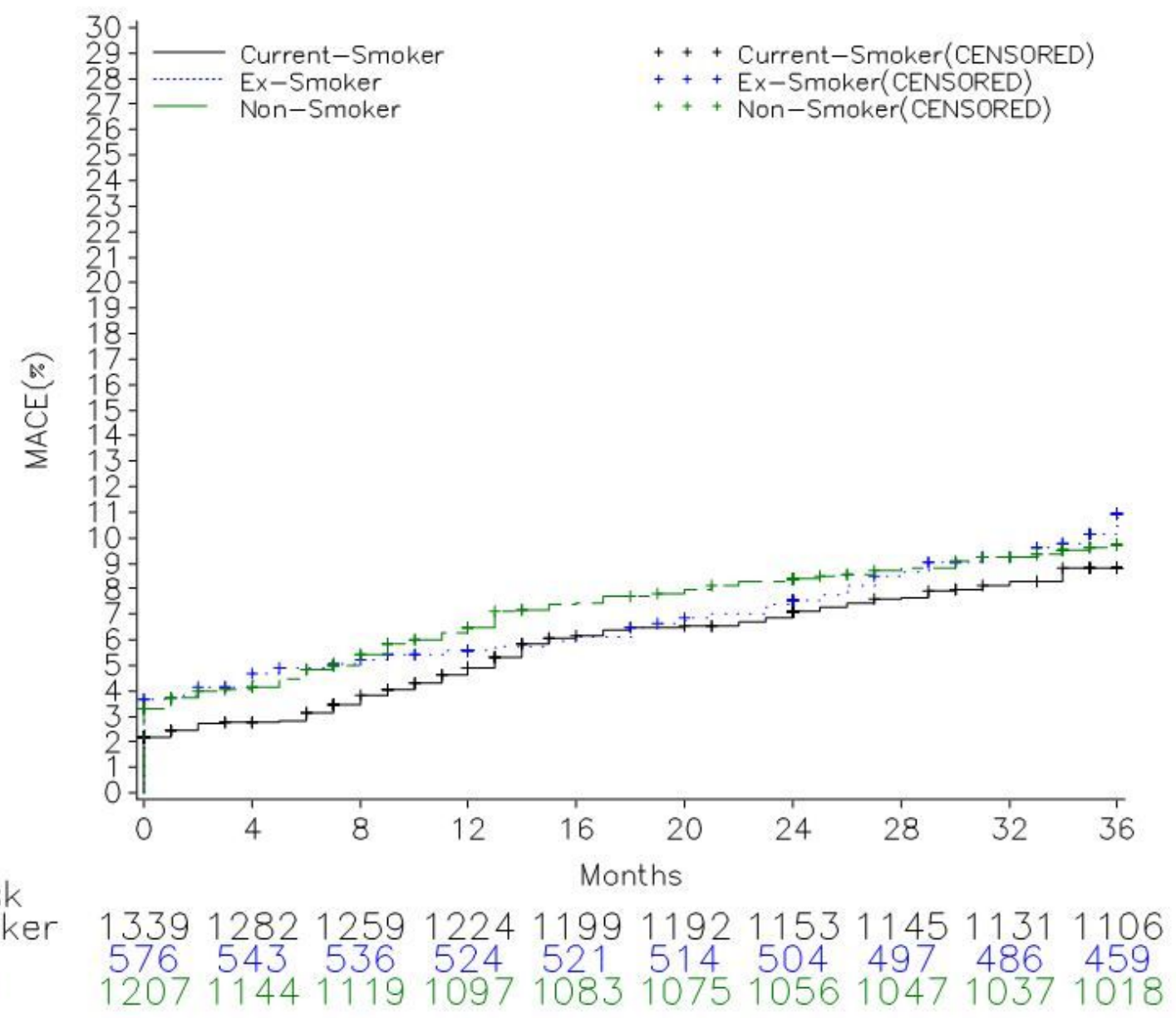

Figure 2

Kaplan-Meier survival curve of MACE 